\title{
Arte e ciência no palco
}

\author{
Art and science on the stage
}

Entrevista com

\section{Carlos Palma}

Diretor do projeto "Arte e Ciência no Palco"

Alameda Lorena, 1080 cj. 3

Jardim Paulista

01424-001 São Paulo - SP - Brasil acpcultural@uol.com.br;

www.arteciencianopalco.com.br/

Entrevista concedida a

Luisa Massarani e

Carla Almeida

(em 19.10.2005)

Centro de Estudos do Museu da Vida

Casa de Oswaldo Cruz/Fiocruz

Av. Brasil 4.365, Manguinhos 21045-900 Rio de Janeiro - RJ Brasil

lumassa@fiocruz.br e

carlalmeida@coc.fiocruz.br
SPALMA, C.: Arte e ciência no palco.

(Entrevista concedida a Luisa Massarani e Carla Almeida). História, Ciências, Saúde - Manguinhos, v. 13 (suplemento), p. 233-46, outubro 2006.

Nesta entrevista sobre a ciência no teatro, o ator Carlos Palma relata sua experiência à frente do projeto "Arte e Ciência no Palco", que, desde 1998, monta peças cujo mote principal são temas ligados à ciência. Ele conta como surgiu a idéia e formou uma equipe para viabilizá-la, e qual o critério para a escolha das peças que monta com o grupo. Fala das dificuldades enfrentadas ao trabalhar temas científicos em um país onde não há dramaturgia disponível sobre o assunto e analisa a resposta do público às suas peças. Palma apresenta ainda reflexões sobre o teatro como ferramenta de divulgação científica.

PALAVRAS-CHAVE: teatro; ciência; teatro e ciência.

PALMA, C.: Art and science on the stage.

(Interviewed by Luisa Massarani and Carla Almeida).

História, Ciências, Saúde - Manguinhos,

v. 13 (supplement), p. 233-46, October 2006.

In this interview about science in the theater, actor Carlos Palma recounts his experience as head of "Art and Science on the Stage," a project that has been presenting plays on science topics since 1998.

Palma tells how the idea came to life, how he put together a team to carry it out, and how he chooses the plays to be staged. He also talks about the problems he has encountered in trying to address scientific topics in a country that lacks any dramaturgy in the area. Another topic broached is how the public reacts to his plays. Lastly, Palma offers his reflections on theater as a tool for public science education.

KEYWORDS: theater; science; theater and science. 
A o longo da última década, o ator Carlos Palma vem se destacando no cenário brasileiro por estar à frente de vários espetáculos teatrais sobre temas ligados à ciência. $\mathrm{O}$ repertório do projeto "Arte e Ciência no Palco", dirigido por ele, inclui hoje uma dezena de peças científicas destinadas a adultos e ao público infantil, ejá recebeu cerca de 600 mil espectadores.

Foi no campo da dramaturgia que se construiu a trajetória desse profissional. Seu contato com a ciência ocorreu quase que por acaso. Encantado com a montagem chilena do monólogo Einstein, escrito pelo canadense Gabriel Emanuel, que viu em 1995, Palma comprou os direitos autorais da peça e estreou sua montagem em 1998, em São Paulo. O trabalho lhe rendeu o Prêmio Mambembe de melhor ator e tornou-se o início do "Arte e Ciência no Palco".

Cercado por entusiastas da divulgação científica, que o incentivaram a seguir esse caminho, Carlos Palma tomou conhecimento da repercussão internacional da peça Copenhagen, do britânico Michael Frayn, e decidiu montá-la no Brasil. Vencedora do Prêmio Qualidade Brasil de 2001, nas categorias de melhor direção e melhor espetáculo, e do Prêmio Estímulo Flávio Rangel 2001, Copenhagen consolidou o trabalho do grupo, hoje formado por sete atores.

"O que o teatro faz é pensar a nossa existência, a nossa vida; se a ciência faz parte da nossa vida, então ela tem que estar no teatro", afirma Palma. Para ele, o teatro é uma ferramenta poderosa de divulgação científica, capaz de levar ao público a ciência em primeiro plano e de estimular a reflexão sobre a relação entre ciência e sociedade.

Nesta entrevista, Carlos Palma fala sobre o "Arte e Ciência no Palco" - como foi criado, as dificuldades que enfrenta, êxitos e desafios, bem como trabalhos futuros. Ele também reforça o compromisso que o grupo tem com a divulgação científica.

\section{Ciência e teatro podem estar de fato juntos?}

Tenho certeza que sim. Podemos muito bem, através do trabalho artístico, colocar o conhecimento científico como foco de atenção. Acho plausível trazer conhecimentos mais contundentes da realidade, do homem, da natureza e da vida para a arte. A ciência faz parte da cultura do homem; está junto a tudo que se faz na arte. Existe toda uma tecnologia que colabora com a produção artística, seja no teatro, seja no cinema ou na literatura. Não vejo dificuldade alguma em trazer a ciência para o centro da arte. Por exemplo, a iluminação é essencial ao teatro e há, por trás dela, uma tecnologia e um avanço científico, mas eu posso, além de utilizar diretamente essa tecnologia, trazer o conhecimento científico da luz e da ótica para o palco e usar isso para provocar uma discussão sobre o avanço do conhecimento humano. 
Você já disse em outras entrevistas que não gostava de ciência quando era criança. Como você passou a se interessar por essa área?

É verdade, eu não dava a menor bola para a ciência. Só fui me interessar por ela com Einstein [peça de Gabriel Emanuel]. Isso foi em 1995, quando assisti ao espetáculo no Chile. Fiquei muito entusiasmado com o que vi. Dois anos depois, compramos os direitos autorais da peça. Com o texto na mão é que fui ver o que Einstein queria dizer com isto e aquilo, foi aí que comecei a ler e a pesquisar aquilo que eu devia ter aprendido na escola.

A que você atribui essa sua falta de interesse pela ciência na idade escolar?

Quando eu estava ingressando no ensino médio, tive que optar entre fazer o segundo grau científico, que compreendia as áreas científicas, ou o clássico, que compreendia as áreas humanas. Esta separação das áreas de conhecimento, embora necessária, ocorria de maneira muito abrupta. Em momento algum poderiam se conciliar as duas coisas para se ter uma visão mais abrangente do mundo. Como eu gostava de desenhar, pintar e ler, e tinha dificuldade com matemática, que achava muito chata e não conseguia aprender, o caminho natural foi escolher o curso clássico. Depois acabei cursando o segundo grau normal, mas continuei tocando minha vida no caminho da arte, do teatro e da pintura, e trabalhei muitos anos com publicidade. Eu ignorava tudo que fosse relativo às ciências naturais. Acho que isso se deve à conjuntura da época. A separação artificial do mundo vingou no final dos anos 60 e nos anos 70. Na década de 1980, essa separação começou a ser questionada, mas ainda de maneira branda. Nos anos 90 é que houve de fato um insight na sociedade, que não considera mais possível tanta separação. No meu caso particular, foi Einstein que me deu a luz. Einstein foi fantástico comigo.

Quando decidiu montar a peça Einstein, já havia the ocorrido a idéia de adotar a temática da ciência no teatro de forma sistemática?

Não, isso ainda demorou. O que me interessou em Einstein foram as questões humanas do personagem. Mas, para entender Einstein como pessoa social e existencial, eu tinha que entender o que ele fez e o que ele dizia na peça. Se ele falava sobre a deflexão da luz, eu tinha que saber o que era esse negócio; se dizia que o espaço se curva na presença de uma massa enorme, era preciso entender o significado disso. Foi aí que comecei a ler sobre sua obra. Dei um pulo bem grande, nem passei pela física clássica e já fui para a moderna, procurei entender o que era relatividade, espaço e tempo. Aos poucos, fui percebendo o quanto era artístico o que ele propunha. Foi isto que achei bacana. Mas esse envolvimento era apenas parte da preparação do personagem para aquela peça específica. Fui fisgado de fato pela ciência no Rio de Janeiro. Quando fomos 
para aquela cidade em agosto de 1999 - a peça estreou em São Paulo em março de 1998 - tive contato com pessoas ligadas à divulgação científica da Casa da Ciência, como o Ildeu [Moreira] e a Fátima [Brito]. Foi assim que conheci esse espaço que busca a reconciliação entre a arte e a ciência. Eu tinha acabado de receber o prêmio Mambembe de 1998 por Einstein e estava vivendo o dilema de qual seria meu próximo trabalho. Decidi então continuar fa-lando de ciências exatas e naturais no teatro. Assim nasceu o projeto "Arte e Ciência no Palco". Houve a grande coincidência de, ao pensar nisso, Ildeu lembrar que havia uma peça chamada Copenhagen, que foi nosso trabalho seguinte.

Como foi o trabalho de formação de uma equipe interessada em trabalhar temas científicos?

Foi difícil e continua sendo difícil. Os atores estão em busca de trabalho, mas é difícil falar para eles: "Olha, você vai ter que ler um pouco sobre fotossíntese, sobre DNA...". É muito mais fácil - sem querer minimizar o trabalho de outros - montar um grupo que vai tratar de questões sociais, da miséria, da distribuição de renda e dos regimes políticos. Esses temas são muito mais envolventes,

Cena da peça “Einstein”. Foto de divulgação. 
porque as pessoas têm uma relação mais estreita com eles. Quando o assunto é ciência, as pessoas se perguntam: “Qual a minha relação com isso?". Elas não sabem. É mais fácil ver aproximação com as questões sociais do que com a ciência. Em São Paulo, ou acham que nosso teatro é para a elite - o que não é verdade - ou acham que fazemos um trabalho didático, para escolas, o que também não é verdade.

Falta então percepção de que a ciência é parte da cultura?

Total. A vida é simples, é só tentar buscar o entendimento do todo. Quando queremos entender o todo, não podemos ignorar a ciência, parte integrante da sociedade, da economia, das nossas ações e da nossa vida. Ainda é difícil, mesmo no espectro da arte, as pessoas enxergarem isso com mais clareza.

\section{Como as peças são escolhidas?}

Também é difícil, porque não há uma dramaturgia disponível sobre temas científicos. As pessoas não se dão conta do enorme potencial que tem o teatro sobre ciência. Em nosso repertório, temos poucos textos de nossa autoria. Foi muito difícil para Oswaldo [Mendes], por exemplo, escrever $A$ dança do universo. Houve mudanças no texto até o momento da produção do espetáculo. Além deste, temos dois textos infantis de nossa autoria, o Da Vinci pintando o sete e o 20.000 léguas submarinas... ufa!, que é uma adaptação da história de Júlio Verne. Hoje, temos alguma rede de contatos, que se amplia cada vez mais, com pessoas de outros países que fazem esse tipo de trabalho.

Como é essa troca entre países que desenvolvem trabalhos de ciência no teatro?

Não é muito grande. Poderia ser muito maior. Mas como vamos interagir? Não dá, é desigual demais. A Inglaterra e os Estados Unidos, por exemplo, estão muito à frente de nós. Precisamos muito mais deles do que eles de nós. Copenhagen é do inglês Michael Frayn, Perdida, uma comédia quântica é do espanhol José Sanchis Sinisterra, Quebrando Códigos é do inglês Hugh Whitemore, E agora Sr. Feynman? é do norte-americano Peter Parnell. E os próximos textos que iremos produzir também não são brasileiros. Um é norte-americano, e o outro, inglês. Não tem jeito.

Como os atores se preparam para interpretar os personagens?

Nosso grupo é formado por sete atores, além dos técnicos. Nem todos estão no mesmo patamar de conhecimento científico. Para cada peça que montamos, estudamos um tema diferente, discutimos em grupo e o ator acaba aprendendo e se interessando pelo assunto. Também conversamos muito com especialistas no tema que vamos 
tratar. Os pesquisadores da Universidade de São Paulo, por exemplo, vêm sendo muito prestativos e generosos, nos ajudando de diversas maneiras. Além disso, há professores e pessoas ligadas à comunidade acadêmica que passam $e$-mails oferecendo ajuda. Acabamos formando uma massa crítica de pessoas que colaboram, e isso é fantástico. Cria-se uma relação muito bacana entre os atores e os cientistas. Nenhum dos dois lados tem resistência a aceitar o caminho que está sendo adotado. Não há conflito em nossas relações.

Os espetáculos do "Arte e Ciência no Palco" trabalham principalmente temas e personagens históricos da ciência. Isto é proposital?

De maneira geral, trabalhar em cima de fatos históricos em vez de usar a ficção é também o que se faz lá fora. Primeiro porque esses personagens históricos são sempre atraentes, seja um artista de cinema, um escritor ou um cientista. Quando alguém faz algo de importante, queremos saber como foi a vida dessa pessoa. Trabalhar com ficção já é mais complicado, porque exige uma criatividade tremenda. Todas as nossas peças, com exceção de Perdida, que é uma ficção, tratam de personagens históricos. Essas peças podem contribuir, de certa maneira, para a formação intelectual das pessoas. Muitos não leriam um livro sobre a vida de Einstein, mas assistiriam a uma peça sobre ele. O teatro, ao representar esses personagens e todo o mundo artístico a seu redor, torna essas histórias atraentes. Em uma hora e meia de espetáculo, as pessoas aprendem alguma coisa sobre esses personagens, divertindo-se e se emocionando.

Pensando no caminho inverso, você ach a que o teatro científico pode ser um ponto de partida para um aprofundamento maior sobre determinado tema? Por exemplo, alguém que assista a Einstein pode se interessar em saber mais sobre sua vida?

Acho que tem, sim, esse efeito de estimular. Acredito que grande parcela do nosso público seja estimulada a ir mais fundo no assunto da peça. Tem gente que acha que contar a vida de Einstein em uma hora e dez é ser reducionista. Mas eu diria que não há perdas nessa redução. Trata-se de uma outra situação, de outra dimensão na compreensão do personagem e que vai levar algumas pessoas a abrirem o livro de Abraham Pais ou ler outra obra sobre Einstein. Por outro lado, se alguém assistir à peça Quebrando códigos e quiser conhecer vida e obra de Alan Turing em detalhes, não vai poder, porque ainda não foi publicado em português um livro sobre ele. $\mathrm{O}$ cinema também tem um papel importante neste sentido. Antes de Uma mente brilhante, por exemplo, ninguém sabia quem era John Nash, um matemático que revolucionou as teorias econômicas. Incrível! A arte tem esse dom de provocar, de despertar as pessoas, algo mais que o seu dia-a-dia lhe oferece. 


\section{1}

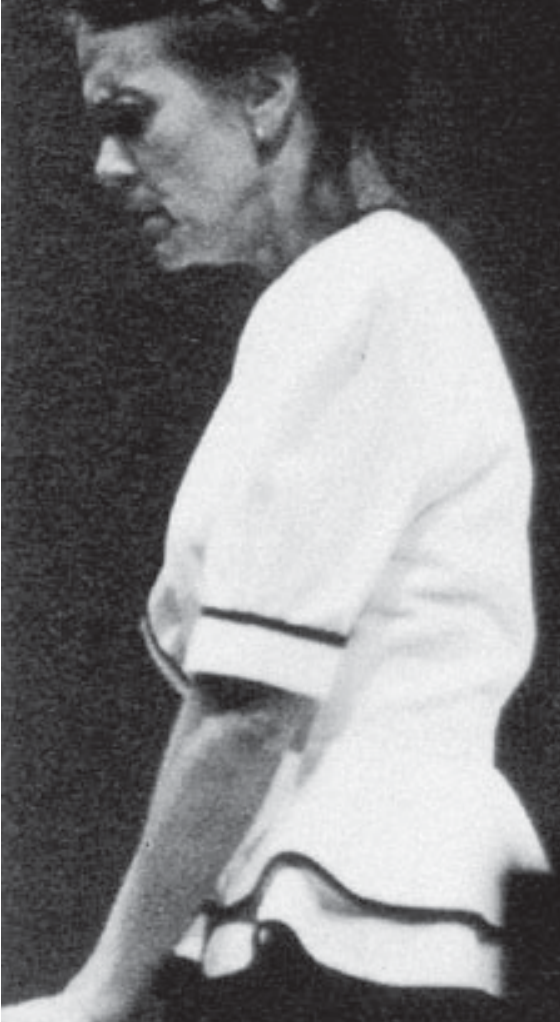

Cena da peça "Copenhagen". Foto de divulgação.
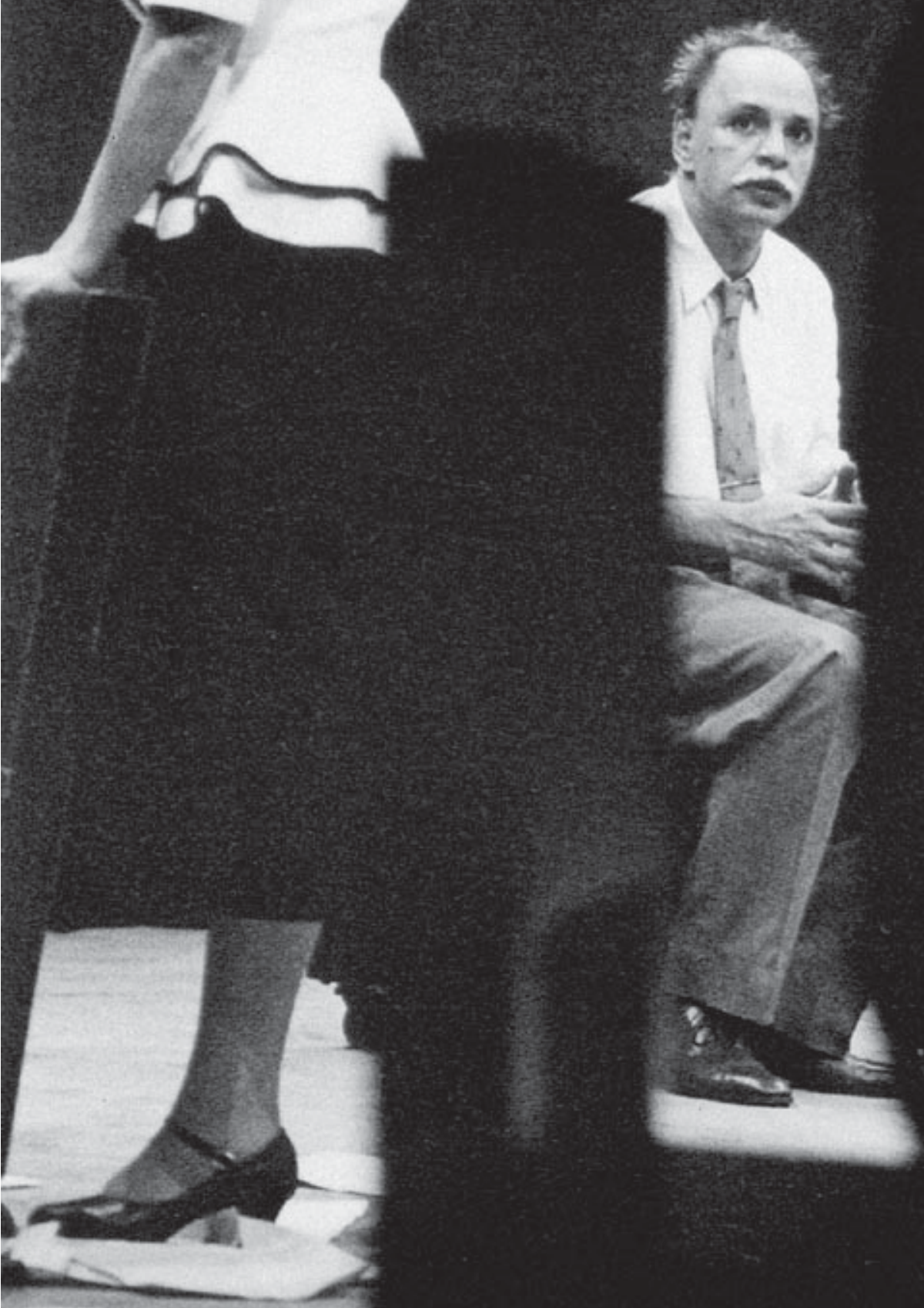
Cientistas brasileiros e temáticas nacionais estão nos planos do "Arte e Ciência no Palco"?

Eu queria montar uma peça que falasse sobre a biodiversidade. Esta é uma questão premente. Estamos vivendo hoje uma situação muito dramática; abrimos as páginas dos jornais e vemos estampado na capa aquele rio seco com milhares de peixes mortos e um cara num barco sem poder se locomover porque não tem água. E tudo por causa da atitude predatória do ser humano, que explora a natureza deliberadamente. Gostaria de falar da água, do ar, da riqueza natural que temos e que está sendo explorada indevidamente por grandes laboratórios e por empresas multinacionais. Queria deixar as pessoas em estado de choque e mostrar que estamos vivendo no limite. Acho que seria importante trazer esta questão para o teatro. Também queria trabalhar em cima de personalidades brasileiras como Santos Dumont, Oswaldo Cruz, Cesar Lattes, Carlos Chagas...

Você mencionou a carência, no Brasil, de dramaturgia sobre temas científicos e a falta de atores dispostos a trabalhar nessa área. Que outras dificuldades você enfrenta na hora de montar um espetáculo sobre ciência?

Vou dar o exemplo de Einstein. As explicações que dou na peça sobre a curvatura do espaço e sobre a relatividade são práticas. Esta é uma dificuldade. Para não ficar apenas na teoria e no didatismo, é preciso construir metáforas, dar exemplos concretos, porque o público precisa ver para acreditar. Mas como fazer experimentos durante um espetáculo de menos de duas horas? Como achar espaço para apresentar os conflitos morais do personagem e da sociedade, oferecer um panorama do contexto histórico em que viveu determinado cientista e ainda mostrar suas idéias e descobertas de maneira prática? Esta é mais uma das dificuldades e um desafio para o encenador. No Feynman, por exemplo, tivemos esse problema. Como falar dos elétrons se não podemos vê-los? Como vou fazer esta transposição para algo concreto?

Copenhagen, na versão britânica, tinha como marca a ausência de cenário, sem música - à exceção de algumas cenas que, justamente pela ausência nos outros trechos, tinham grande impacto. A versão brasileira optou por abrir mão disso. Por quê? E como avalia o resultado final?

Assisti apenas à montagem norte-americana, cujo diretor é o mesmo da produção inglesa. Na americana, havia três inserções musicais, ou de ruídos: a campainha, uma gaivota e a bomba atômica. Sinceramente, achei chato demais. Mas há uma razão para ser assim. Os ingleses e os norte-americanos estiveram envolvidos diretamente com essa questão. Para eles, falar de bomba atômica e de Segunda Guerra Mundial é difícil, está na carne. Agora, imagina fazer isso aqui no Brasil, com todo o nosso espírito latino e vigor 
emocional. Acho que ninguém iria suportar. Então, em vez de fazer uma peça sem emoção, como a que vi nos Estados Unidos, Marco Antonio Rodrigues decidiu transformar a discussão do Bohr e do Heisenberg em algo mais intenso, com mais emoção, porque nós brasileiros somos assim. Marco Antônio não viu a montagem norteamericana, mas viu a inglesa. Durante os quatro meses e meio em que montamos a peça, conversamos muito sobre isso e acho que escolhemos o caminho mais adequado.

Houve algum retorno do público internacional em relação a essas modificações?

Michael Frayn [autor de Copenhagen] falou, em entrevista concedida a $O$ Estado de S. Paulo, sobre a montagem brasileira. Ele disse que não viu, mas que tinha ouvido elogios sobre as mudanças na montagem brasileira. Nós acabamos de apresentar a peça em Portugal e foi um arraso. Isto foi logo depois de a montagem inglesa [adaptada para o português] sair de temporada. Conheci Carmen Delaways, a atriz que interpretou Margareth Bohr. Ela e o ator que interpretou o Bohr foram assistir à nossa montagem e ficaram entusiasmadíssimos, pois viram como a arte permite mil leituras de uma mesma obra. Eles disseram: "Vocês foram aonde não imaginávamos ser possível ir, realizaram muito bem isso e é muito provocante". Muita gente que havia assistido à montagem inglesa foi ver novamente. Algumas pessoas confessaram ter preferido a nossa.

Em outras peças, também foi necessário fazer adaptações para o público brasileiro?

Em todas elas. Feynman, por exemplo, é um texto norte-americano que fala dos últimos anos da vida do cientista, que está com câncer. Ao ler o texto, e conhecendo a vida do Feynman, vimos que era preciso mexer em algumas coisas. Por exemplo: Feynman morou no Rio de Janeiro, saiu em escola de samba na década de 1950 e era apaixonado pelo Brasil; tínhamos que acrescentar isso. Temos sempre a preocupação de apresentar a peça para o nosso público. A montagem inglesa de Quebrando códigos, para dar outro exemplo, era uma montagem realista. Fizemos nossa montagem mais minimalista, com poucas coisas, dando ênfase ao texto e à interpretação do ator. Cada diretor faz a sua leitura.

\section{Qual o público alvo da companhia "Arte e Ciência no Palco"?}

De certa maneira, nosso trabalho tem colaborado com professores e educadores, um público um tanto abandonado. Eles recebem mal, têm uma carga horária pesada de trabalho, dão aula em quinhentas escolas para poder ganhar o mínimo... Temos recebido muitos professores e pessoas ligadas à área de educação, o que é 
muito positivo porque, sem o professor, não adianta mostrar as peças para os alunos das escolas. Se os alunos estão mal informados, cria-se um buraco entre o que estamos fazendo e eles. Quando divulgamos as peças, há uma aproximação muito grande com o corpo docente. Eles se desarmam para assistir ao espetáculo, voltam para as escolas, preparam seus alunos e depois trazem a turma para ver a peça. Fomos descobrindo aos poucos nossa preocupação em dar atenção ao professor, porque é ele quem está no topo e vai formar quem está lá embaixo. Este caminho não dá para reverter.

Já é possível medir o impacto do projeto de vocês no trabalho de educadores?

Percebemos uma grande repercussão do nosso trabalho entre professores, um vai falando para o outro, que vai falando para o outro. Assim, nosso trabalho vai se multiplicando. Às vezes, acontecem coisas interessantes que mostram esse impacto. Por exemplo, um aluno que assistiu a Einstein há sete anos está se formando em física e quer mostrar a peça aos colegas de sua cidade. Tem uma professora que viu Einstein há três anos e que só agora conseguiu levar a peça para a escola dela. Foi um espetáculo maravilhoso, com todo o corpo de professores da escola, a direção e os alunos, que estavam muito bem preparados. Ela disse que demorou porque teve dificuldades na escola para financiar a apresentação, mas que, além disso, queria preparar os alunos. Isto não pode parar. Se falarmos que vamos acabar com o projeto "Arte e Ciência no Palco", eles não vão deixar.

Qual a diferença entre montar espetáculos para adultos e para crianças?

No caso das crianças, tenho a convicção de que é preciso trabalhar com o lúdico, com o jogo. Isto tem que estar em primeiro plano, porque faz parte do universo delas. O lúdico faz parte do universo de todos nós, mas, para as crianças, ele tem um significado muito forte. No caso de $\mathrm{Da}$ Vinci pintando o sete, por exemplo, Da Vinci não era o pintor e sim o inventor e, mais do que o inventor, era o homem que não se desestimulava diante do fracasso. Ele desenhava, fazia seus protótipos, dava tudo errado, ele caía do avião... Enfim, isto, para a criança, é engraçado e ao mesmo tempo pedagogicamente importante. É bom ela ter a noção de que a ciência é feita de tentativas e erros. No caso das 20.000 léguas submarinas...ufa!, resgatamos um pouco Júlio Verne e seu dom de antecipar os acontecimentos. Mostramos assim que é possível, através da arte, antecipar fatos. Acho que, com crianças, o importante é deixá-las livres para serem curiosas, estimulá-las a perguntar, não inibi-las e contar a história bem contada. 
Vocêse considera um divulgador de ciência?

Sou um artista e a minha arte é o teatro. Mas, através do teatro, posso colaborar com a divulgação científica. Não sei em que medida, mas acho que estamos colaborando com esse movimento e me sinto honrado de estar fazendo isto. Sinto o maior orgulho de estar junto de pessoas como a Luisa [Massarani] e o Ildeu [Moreira]; estas sim são as pessoas importantes para a divulgação científica. Elas têm um trabalho importante a fazer e estou aprendendo com elas. Sintome à vontade para falar que fazemos parte desse movimento de divulgação científica. Fazemos arte, mas também fazemos divulgação científica com a arte.

Fernando Paz e Adriana

Dham em cena da peça

infanto-juvenil "Duas mil

léguas submarinas”, exibida

em 2004.

Foto de divulgação.
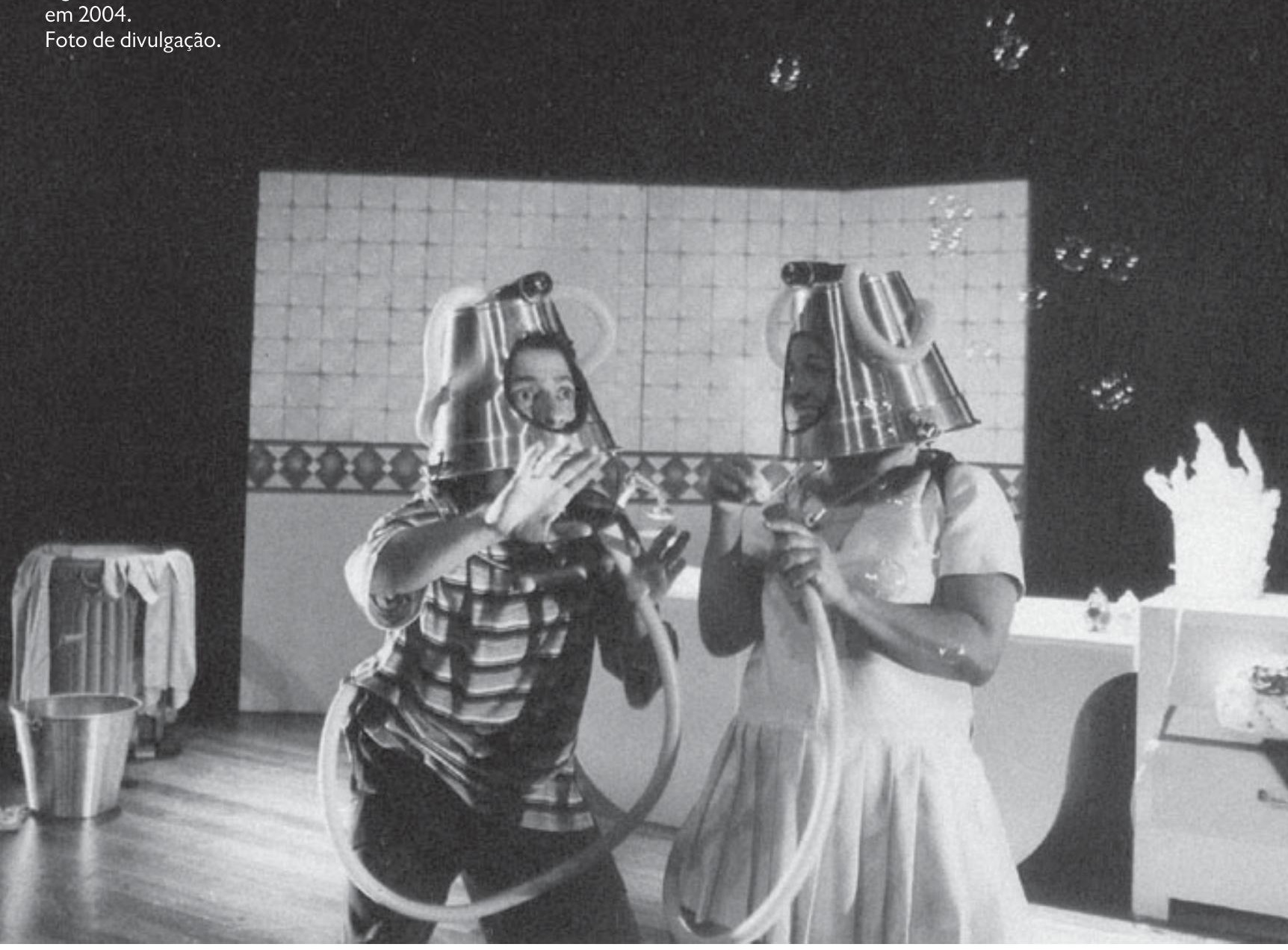
Como você avalia o teatro como ferramenta de divulgação científica?

O teatro é uma ferramenta poderosíssima, capaz de levar ao público a ciência em primeiro plano. Mas, ao mesmo tempo em que é fácil fazer teatro, também ele pode ser a coisa mais difícil de ser feita. É fácil no sentido de que estamos aqui tendo um diálogo e isso pode virar uma peça de teatro. Agora, transformar isto em algo de impacto é que não é trivial. Se não conseguirmos impactar as pessoas, chegar dentro delas, não adianta, porque há uma barreira cultural e psicológica que está ali o tempo todo. Sempre acho que as pessoas vêm com disponibilidade para aceitar a ilusão do teatro, a arte teatral, mas tem gente que vem para acompanhar alguém, então, temos que quebrar essas barreiras e entrar dentro de cada um.

Qual a diferença entre divulgar ciência através do teatro e através do cinema?

O cinema é uma tela na sua frente e ponto final. As pessoas podem comer pipoca, sair... não estão nem aí. No teatro é diferente. Há poucas pessoas que estão dispostas a se concentrar para aquele momento, que é um ritual. Eu me preparo para entrar em cena uma hora antes de começar a peça - fico me maquiando, pensando sobre meu personagem, respirando...-, a platéia também se prepara para vir ao teatro. As pessoas sabem que estarão na frente de um ator, de uma cenografia, e que estarão à mercê dos efeitos ali presentes, diferentemente do que acontece no cinema. Mas considero tanto o cinema quanto o teatro ferramentas muito poderosas de divulgação científica e, se o cinema tem colaborado tanto com isto, o teatro, que deixou isto de lado ou não se ateve a essa questão, tem que pegar o caminho e colaborar também com a divulgação científica. Acho que é importante.

O teatro e outras manifestações artísticas têm sido usados como ferramentas para falar de ciência, no entanto, é raro ver a situação inversa, o artista usando a ciência para se comunicar. Por que você acha que isso ocorre?

A pessoa que faz ciência pode pegar facilmente as técnicas de improvisação do teatro e montar uma historinha dentro da sala de aula para facilitar o entendimento da ciência. Neste caso, a arte está sendo usada para tornar a ciência mais palatável ou para facilitar o ensino da ciência. O inverso é mais difícil, porque o artista é livre para trabalhar determinada questão da forma que desejar. Claro que temos que respeitar o viés do conhecimento, mas trazemos a questão dos conflitos humanos, da responsabilidade científica, dos valores da ciência, da ética da ciência, pois são estes aspectos da ciência que nos interessam. A função da arte é mostrar que a vida mudou com a ciência, e vai mudar mais. O que o teatro faz é pensar a nossa existência, a nossa vida. Se a ciência faz parte da nossa vida, então ela tem que estar no teatro. Agora, como isso vira obra de arte é um problema do artista. 
Até onde vai a liberdade artística e a correção científica?

Não se pode querer liberdade para mudar a teoria de Einstein, não dá, é melhor fazer outra coisa. Quando o artista se apropria de temas do conhecimento humano, principalmente no que se refere às áreas exatas e científicas, não pode deturpá-las, é preciso trabalhar com os fatos reais. Mas há situações em que o artista, usando o bom senso, decide alterar alguns fatos para tornar a história mais interessante. Em $A$ dança do universo, por exemplo, Oswaldo criou um encontro fictício entre Kepler e Galileu, no qual buscamos mostrar a essência de quem era Kepler e de quem era Galileu. Mesmo sendo plausível que eles tivessem tido esse tipo de diálogo, houve neste ponto uma liberdade de criação. Nessa mesma peça, fizemos intuitivamente algumas mudanças que acabaram coincidindo com a verdade. Precisávamos realizar uma cena de 15 minutos em que Newton falasse sobre suas teorias. Como seria chato ficar só no diálogo, decidimos colocar nessa cena ele montando o Disco de Newton. Depois vieram me falar que isso era genial, porque poucos sabem que Newton não era apenas um teórico, era um prático, um cientista que colocava a mão na massa e construía coisas para provar suas idéias.

Já houve alguma reclamação, por parte de cientistas ou divulgadores da ciência, em relação a essas modificações feitas por vocês?

Uma vez, quando estávamos em cartaz com $A$ dança do universo, a filha do pesquisador Mario Schenberg, um dos personagens da peça, chamou a nossa atenção: "Meu pai não usava homeopatia, quem usava era a minha mãe". Oswaldo explicou por que tinha tomado a decisão de mudar isto. Ela entendeu e até gostou muito. Nossa relação com divulgadores, educadores e pesquisadores é uma questão de diálogo franco e aberto. Algumas pessoas já me chamaram a atenção, dizendo que Einstein não teria dito isso ou aquilo. Mostro onde tive acesso a tais informações, para tirar a limpo. Mas são detalhes bobos. Às vezes, as pessoas querem mais explicações do que a peça permite como obra de arte.

\section{Como você avalia a trajetória do "Projeto Arte e Ciência no Palco"?}

O projeto nasceu há seis anos, ainda acho cedo para fazermos um balanço. Por sermos um grupo autônomo, ainda temos dificuldades para sustentar nosso trabalho. Estamos sempre correndo atrás de nossa sobrevivência, mas é preciso ter equilíbrio. Não vamos abrir mão do que queremos para ganhar mais dinheiro. Temos hoje três bases de sustentação. Uma é o patrocínio, que vem de duas empresas, Interprint e Etapa; temos a receita de bilheteria, pequena, mas que ajuda; e temos a venda dos espetáculos. A combinação disso permite que a gente vá sonhando, vivendo nosso diaa-dia e produzindo. 
Qual é o desafio que se impõe para o futuro?

Nosso objetivo é ter um repertório rico de espetáculos e um grupo grande de atores, de modo que seja possível apresentar, simultaneamente, uma peça no Rio, outra na Paraíba... Isto ainda é uma utopia, mas estamos indo atrás dela, isso já está acontecendo um pouco. Às vezes acontece de eu estar fazendo Einstein no Rio e Oswaldo e Monika [Plöger] estarem fazendo Feynman em outro lugar. O problema é que alguns atores fazem várias peças, o que impede apresentações simultâneas. Nossas peças precisam circular com mais intensidade, com mais gente, fortalecendo o grupo.

Dois espetáculos entrarão em breve para o repertório do grupo, Oxigênio e Darwin. Em que pé está a montagem dessas peças?

Estamos promovendo um ciclo de leituras na Casa do Saber, em São Paulo. Vamos fazer uma leitura pública do texto de Darwin e depois de Oxigênio, que será nossa próxima estréia. Convidamos as pessoas para assistir às leituras e depois participar de um debate sobre o conteúdo. Precisamos organizar atividades paralelas à produção de espetáculos, porque isso atrai pessoas para assistir às peças e alimenta nosso trabalho. Queremos fazer um ciclo de debates sobre Oxigênio, discutindo a química, o prêmio Nobel, a primazia da descoberta científica e outros temas relacionados ao livro. Gravamos todos esses debates e depois ouvimos as questões colocadas pelo público, o que ajuda na montagem dos espetáculos. Acho muito importante fazer esse trabalho.

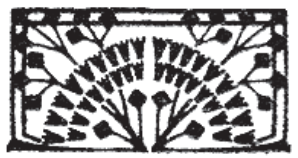

